\title{
@ccreative
}

BY-NC-SA 4.0

UMÁTICA. Revista sobre Creación y Análisis de la Imagen

\{ISSN: 2659-5354// D.L.: MA- 1628-2018\}

\section{Jugar con la escultura.}

\section{Proceso de creación y estética interactiva en la obra de Miguel Berrocal.}

Playing with sculpture. Creation process and interactive aesthetics in the work of Miguel Berrocal.

SEbAstian GÁmez MiLLÁN

I.E.S. Valle del Azahar, Málaga

\section{Resumen}

A lo largo del siglo XX se ha resaltado la importancia del proceso de creación y la estética interactiva. Dividido en cuatro epígrafes, en este artículo vamos a analizar e interpretar en particular en la obra de Miguel Berrocal: 1) El valor seminal de la imaginación en las artes y en las ciencias; 2) Descubrir dibujando; 3) Códice Berrocaliensis; 4) Estética interactiva, con el fin de argumentar que, a partir de una imaginación creadora, apoyada en la capacidad analítica y descubridora del dibujo, Berrocal desmonta la escultura, explorando la cuarta dimensión, y contribuyendo a incrementar el juego dialógico entre la obra y los receptores.

PALABRAS CLAVE: Proceso de creación, imaginación, dibujo, estética interactiva, aprender jugando

Artículo original

Original Article

Correspondencia

Correspondence

sebastian.gamez@

iesvalledelazahar.com

Financiación

Fundings

Sin financiación

Received: 02.02.2020

Accepted: 17.06 .2020

CÓMO CITAR ESTE TRABAJO / HOW TO CITE THIS PAPER

GÁMEZ, S. (2019). Proceso de creación y estética interactiva en la obra de Miguel Berrocal.

Umática. Revista sobre Creación y Análisis de la Imagen , 2: 15-29.

https://doi.org/10.24310/Umatica.2019.vii2.9610

Umática. 2019; 2: 15-29. 


\section{Playing with Sculpture. Creation process and interactive aesthetics in the work of Miguel Berrocal}

\section{SEbAstian GÁmez MILLÁN}

Filiación, Spain

\section{Abstract:}

Throughout the 2oth century, the importance of the creative process and interactive aesthetics has been emphasised. Divided into four sections, in this article we are going to analyse and interpret in particular the work of Miguel Berrocal: 1) The seminal value of imagination in arts and sciences; 2) Discover by drawing; 3) Codex Berrocaliensis; 4) J Interactive aesthetics, in order to argue that, based on a creative imagination, supported by the analytical and discovering capacity of drawing, Berrocal dismantles the sculpture, exploring the fourth dimension, and helping to increase the dialogical game between the work and the receivers.

Summary - Sumario:

1. El valor seminal de la imaginación en las artes y en las ciencias

2. Descubrir dibujando

3. El Códice Berrocaliensis.

4. Estética interactiva 


\section{El valor seminal de la imaginación en las artes y en las ciencias.}

La imaginación creadora es una de las características que nos distinguen como especie animal. Nuestra capacidad de adaptación y superación depende en buena medida de la inteligencia y, dentro de ella, ocupa un espacio fundamental las aplicaciones de la imaginación. De no haber sido por estas y sus innumerables concreciones materiales no hubiéramos logrado transformar el mundo y progresar tal como lo hemos hecho hasta nuestros días y tal como previsiblemente lo seguiremos haciendo, a pesar de los continuas adversidades de la naturaleza.

A diferencia de otras especies biológicas, que lentamente, durante generaciones, se van adaptando al medio, los seres humanos, por medio de las técnicas, las artes y las ciencias, adaptamos el medio a nuestras necesidades, creando una especie de sobrenaturaleza en la que podemos vivir bajo condiciones de mayor bienestar (Ortega y Gasset, 1977). Gracias a la evolución cultural aceleramos los ritmos naturales e incluso ampliamos y multiplicamos aspectos de la naturaleza, como nuestra esperanza de vida.

Sin embargo, salvo contadas excepciones (pienso ahora en Montaigne, Vico, Nietzsche, Albert Einstein, Wallace Stevens), durante muchos siglos tanto en la filosofía como en las ciencias se ha menospreciado el valor intelectual y práctico de la imaginación, quedando relegada al terreno de las artes y de la literatura, esferas que al menos desde Kant carecen de un valor cognitivo comparable al de las ciencias naturales.

No obstante, tengo para mí que durante algunas épocas artes y ciencias caminaron más juntas. Pienso que para grandes artistas como Bruegel, Durero, Leonardo, Miguel Ángel o Alberti, artes y ciencias iban de la mano. Y sus frutos eran tan memorables como perdurables. En la actualidad, en un mundo globalizado y ecléctico, pero bajo el dominio del (mal)llamado arte conceptual (como si hubiera algún arte que no lo fuera de una manera o de otra), a mi parecer una de las deficiencias más notables del arte contemporáneo es la pérdida del oficio, de lo artesanal (Richard Sennet, 2009), de la técnica.

¿Sería posible ver caminar más cerca artes y ciencias bajo el cuidado y el susurro de la imaginación? Como señalara uno de esos científicos y divulgadores que sabía conjugar maravillosamente lo más excelente de las ciencias naturales y humanas, Stephen Jay Gould, "no hay ciencia sin imaginación", del mismo modo que "no hay arte sin hechos" (Gould, 2007: p. 45). Si bien para algunos los "hechos" son exclusivos de las ciencias y la "imaginación" de las artes, en realidad ambas disciplinas requieren de hechos, imaginación, hipótesis, ensayos, errores, experimentación, creatividad... Y otros aspectos que comparten en común. Y, en cualquier caso, como declaró Jay Gould, "para las maravillosas e iluminadoras diferencias entre las ciencias y las humanidades, todo al servicio potencial del único gran objetivo de la sabiduría, será mejor que estemos unidos, o con toda seguridad acabaremos colgados" (Gould, 2010: 320).

Uno de los más grandes artistas de todos los tiempos, Miguel Ángel condensó su poética como escultor en un célebre cuarteto que podríamos traducir así: "Ni el mejor de los artistas tiene (podría concebir) un concepto (una forma) que no circunscriba (no esté 


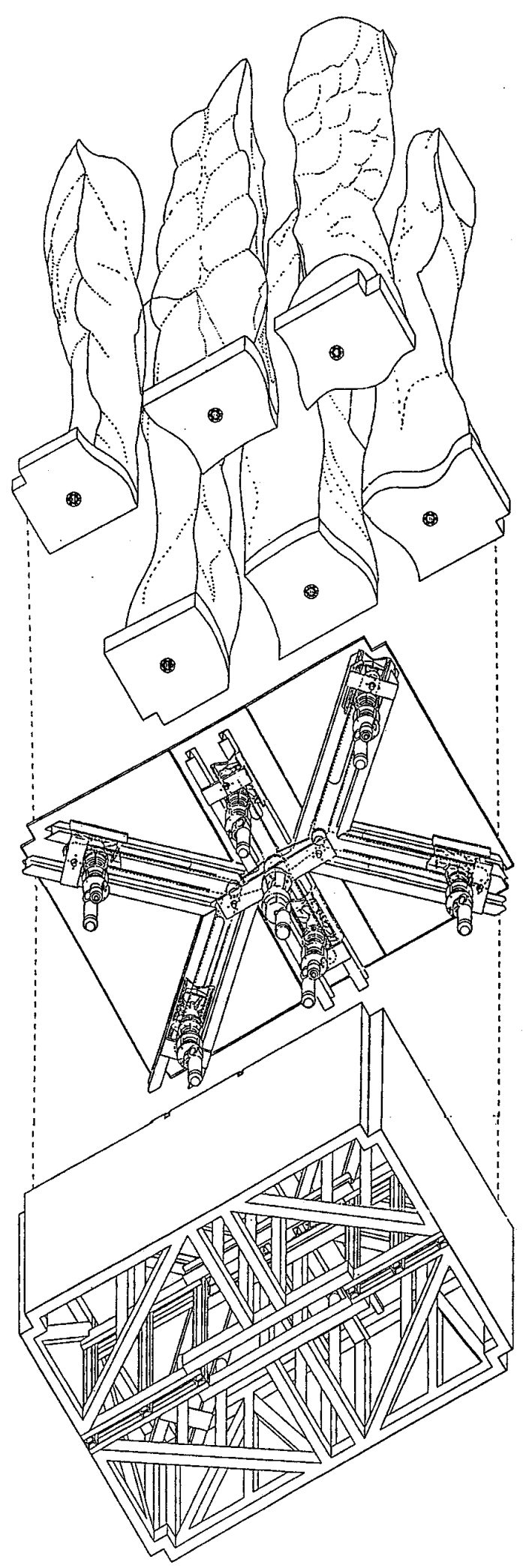

Fig. 1

Citius Altius Fortius

(op. 402) Vista

explotada vertical

Axonometrías

separadas de

las tres partes

que componen

la escultura

(1991)

Fotografía cortesía

de la (C) Fundación

Escultor Berrocal

para las Artes

circunscrita) un mármol solo con sus sobras, pero sólo llega a él la mano que obedece (guiada por) al intelecto" (Gámez Millán, 2018: pp. 154-190). Dicho en otras palabras: en la materia se encuentra en potencia las infinitas formas de la naturaleza (incluso aquellas que no están en ella), sólo es preciso poseer el dominio técnico para seguir con las manos la imagen dibujada que el artista tiene en su mente.

Berrocal, que poseía un dominio técnico de ingeniero, seguía una poética similar a la de Miguel Ángel. Pero antes de adentrarse en la materia elegida, dibujaba con precisión matemática la composición-descomposición, como se aprecia en sus milimétricas axonometrías o en los paralelepípedos (Berrocal, 2000: 65 y 82 respectivamente fig.o1 y fig.02). Esta técnica analítica le permitirá componer y descomponer, montar y desmontar, en definitiva, explorar la llamada cuarta dimensión, rasgo característico y no sé si exclusivo del mundo de Berrocal.

\section{Descubrir dibujando.}

Ahora bien, la imaginación, sin un espacio en el que proyectarse más allá de la mente, como el papel o el lienzo, no puede desplegarse en su infinita potencia. Por eso no es fortuito que el dibujo se pueda considerar la madre de todas las artes plásticas. Es obvio en la pintura ${ }^{1}$ y en la arquitectura

1 El número 253 de la revista Descubrir el Arte contiene tres artículos que trazan una visión panorámica del dibujo desde esta perspectiva 

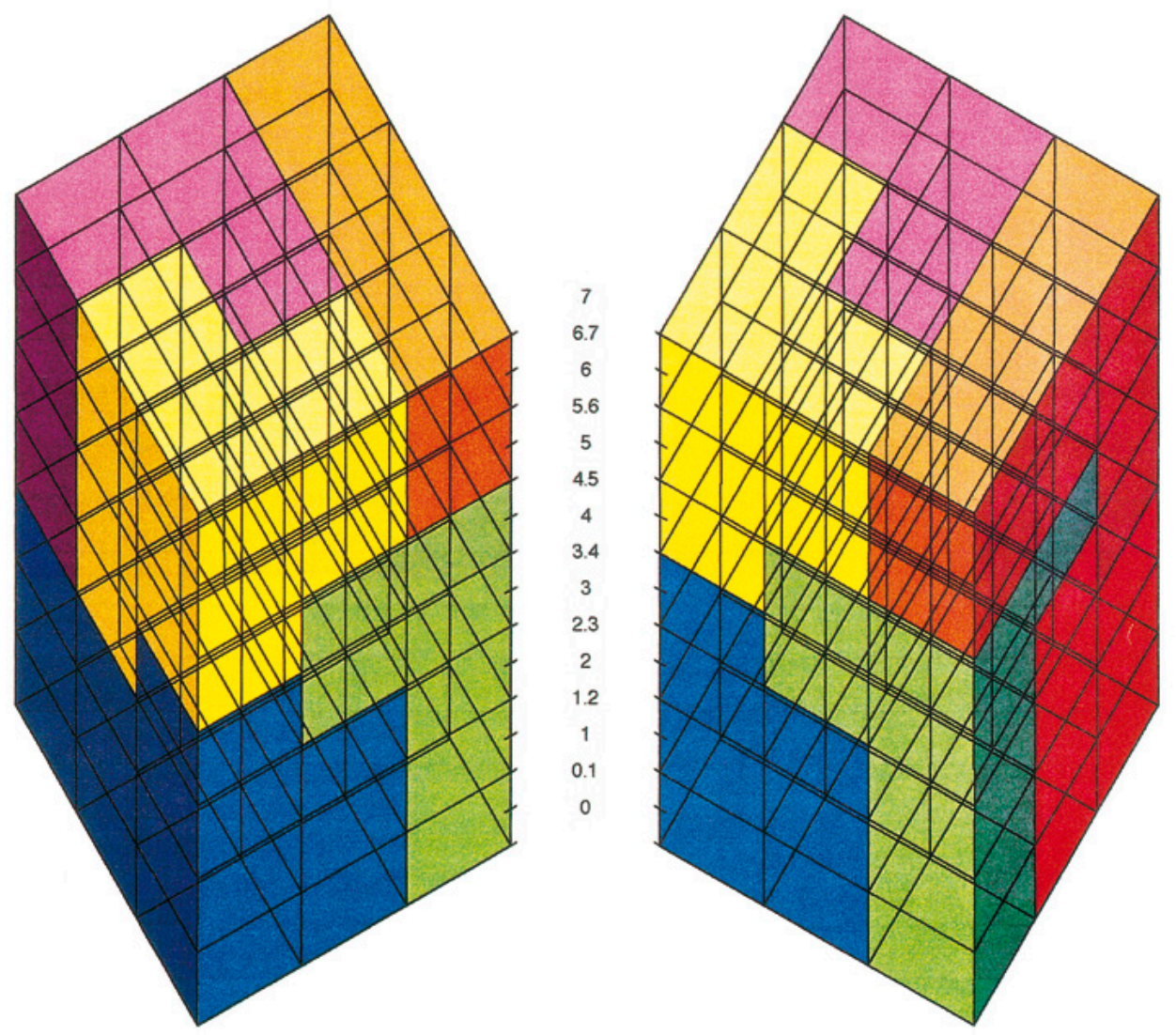

Fig. 2

Adriano Big (op.444) Descripción

Axonométrica del proyecto

$81,5 \times 28,5 \times 32,5 \mathrm{~cm}$ (1994)

Fotografía cortesía de la (Fundación Escultor Berrocal para las Artes

en general: por ejemplo, Norman Foster declaraba que suele llevar un lápiz a mano para dibujar o, lo que equivale a lo mismo, para descubrir formas imprevisibles sin la ayuda de estos. También sucede en la escultura de Berrocal, como hemos sugerido antes y vamos a mostrar a continuación.

¿Podría Berrocal esculpir como lo hizo durante buena parte de su vida sin el apoyo de sus dibujos? Lo dudo. Son piezas de una rigurosa precisión que en muchos casos no hubieran funcionado en el doble sentido del término, estética pero también lúdicamente. Para Berrocal el dibujo posee un valor proyectivo imprescindible. Se diría que sus obras son tan complejas que uno no puede imaginarlas sin antes dibujarlas. Dibujándolas es como llega a verlas.

Con el dibujo no se trata, pues, de una simple copia o mímesis (Tatarkiewicz, 2016: 307-331; Bozal, 1997: 39-102). Como certeramente escribió John Berger: "para el artista dibujar es descubrir" (Berger, 2017: p. 7). De modo que antes de ejecutar sus obras, Berrocal las estudia minuciosa y holísticamente a través de los dibujos, que le permiten ver e imaginar lo que a simple vista no podemos sin la ayuda de estas herramientas, como podemos comprobar en su Estudio-Taller.

Incluso si es factible o no lo puede ensayar mediante dibujos. Hasta que no resuelve los problemas que plantea la obra por medio de axonometrías y paralelepípedos en el plano de la

desde el Renacimiento, pasando por el Barroco, hasta el arte contemporáneo pp. 14-39

Umática. 2019; 2: 15-29 
representación, tal no vez no se decida a ejecutar materialmente la pieza. El principal campo de experimentación transcurre en el espacio imaginario del dibujo. Pero el dibujo no sólo es un medio, al mismo tiempo es un fin en su proceso de creación.

\section{El Códice Berrocaliensis.}

En dos momentos de su vida procuró sintetizar su poética o proceso de creación y, como buen artista, lo hizo de forma artística en el llamado "Códice Berrocaliensis". ¿Qué quiero decir con que lo hizo de forma artística? Que no sólo lo expresa con signos, con palabras, sino al mismo tiempo lo representa, lo muestra con una imagen que expone esa idea. Esto es lo propio del arte frente al ejercicio indisociable de la crítica.

Antes de adentrarnos en él, conviene reparar unos momentos en los títulos de Berrocal: todas las obras van precedidas por el término "Opus" y un número, como si fueran piezas musicales (fijémonos, asimismo, en el diálogo y la confluencia de artes en la escultura de Berrocal: dibujo, escultura, arquitectura, poesía). Y a continuación añade un nombre a menudo no exento de ironía: "Manolita" si el tamaño de la pieza es pequeño; si es grande, "Manolona"; "Elvirita" y "Doña Elvira"... Con este ingenio e ironía, propios del arte moderno (Marina, 1992: 131-16) y posmoderno, rebaja la grandilocuencia a la que se asocia habitualmente el arte.

El "Códice Berrocaliensis" (VVAA, 2000: 118-126) fig.03 que vamos a analizar e interpretar es el que ejecutó en 1985, cuyo subtítulo aclara: "reflexiones acerca de la forma y el color". Son 8 acuarelas sobre papel japón manuscritas en italiano de $46 \times 36 \mathrm{~cm}$. En la primera de ellas leemos: "El volumen negativo del vacío siempre está presente". Como en la estética Oriental (a la luz de lo que han experimentado otros artistas occidentales, ¿no será acaso un fenómeno transcultural?), donde el vacío desempeña un valor esencial, quiere decir que aunque lo represente mediante dibujos está pensando en las tres dimensiones propias de la escultura. Por encima de todo es escultor.

La segunda dice: "La desmontabilidad no debe ser solamente un juego abstracto: por eso he mirado hacia el antropomorfismo". En sentido normativo indica que la desmontabilidad, que es otra de las características singulares de su obra, no es un simple juego, sino más bien una búsqueda que lo ha llevado hacia el antropomorfismo, es decir, las figuras con formas humanas. ¿No es este acaso el origen de la escultura? Para ser original, rasgo que se le exige a los artistas cada vez más desde el Romanticismo a las vanguardias, se necesita no pocas veces remontarse al origen.

Con la tercera vuelve al concepto de antropomorfismo: "La investigación del antropomorfismo me lleva a la metamorfosis de las formas". Se atribuye al filósofo sofista Protágoras la célebre frase "el hombre es la medida de todas las cosas". ¿Podemos salir del antropomorfismo? Quizá de manera parcial y progresiva, pero no sé si completamente. Las artes, las ciencias y, en suma, el conocimiento nos llevan más allá, aun sin salir nunca de nosotros mismos.

Por lo que se refiere al estilo de Berrocal, si en sus comienzos fue más abstracto, a lo largo de su trayectoria juega con un equilibrio entre lo figurativo, que deja entrever y completar con la imaginación qué objeto se representa, y lo abstracto, que lo desfigura para representarlo de 


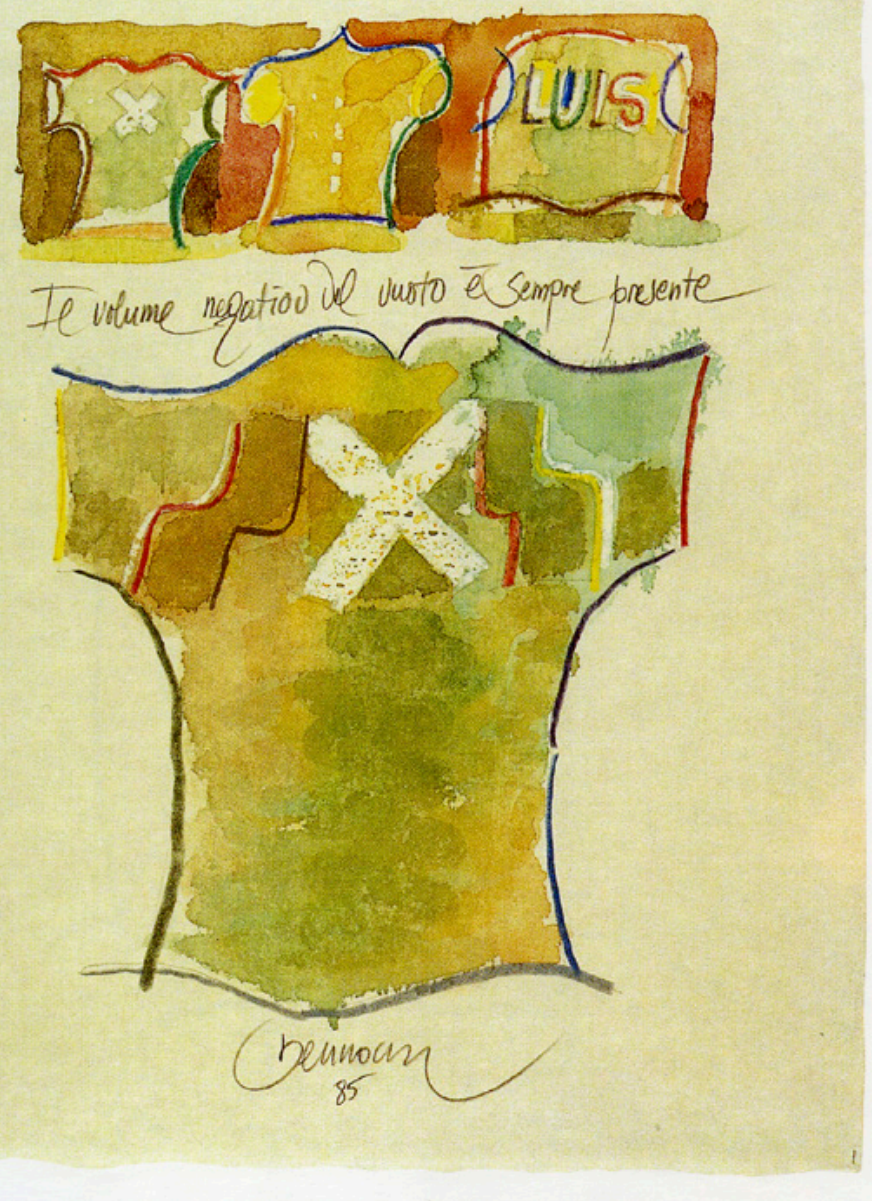

Fig.3

Códice

Berrocalensis 1

"El volumen negativo

del vacío siempre

está presente"

$46 \times 36 \mathrm{~cm}$

Acuarela sobre

papel japón.

(1985)

Colección A.Z.

| Fotografía cortesía

de (C)Fundación

Escultor Berrocal

para las Artes.

otro modo diferente a como lo conocemos tradicionalmente. Una de las funciones del arte es renovar nuestra percepción del mundo que nos rodea y a la vez reconocerlo. Ambas actividades son fuente de placer.

Empleamos el término "abstracción" por comodidad, por economía del lenguaje. Como bien intuyera Picasso, no existe en sentido estricto la abstracción: existen obras más o menos abstractas. Pero si la imaginación, que es el trampolín de la creatividad, se impulsa sobre las convenciones de la memoria, resulta arduo eludir las figuraciones con las que distinguimos unos fenómenos de otros en la realidad. Se diría que la figuración establece el límite entre lo que reconocemos como el ser y el no ser (Gámez Millán: 2018; 90-99).

Ese juego y equilibrio entre lo figurativo y lo abstracto está presente en más aspectos. Por la investigación de sus dibujos, cada detalle es relevante en la escultura de Berrocal: si el conjunto de sus piezas montadas representa una forma que reconocemos transfigurada por la creación en el mundo sensible, al desmontarla cada elemento es más o menos abstracto. Sin embargo, cada pieza no sólo tiene valor estético y útil como parte del conjunto, sino por sí misma. 
"Del signo al volumen se pasa por dos fases: la tercera y la cuarta dimensión", leemos en la cuarta acuarela. Describe el tránsito de sus dibujos a la ejecución material. Con el descubrimiento de la perspectiva durante el Renacimiento, en la pintura se simula de forma imaginaria la tercera dimensión. En cambio, la tercera dimensión es el espacio específico de la escultura frente a otras artes. El deseo de ir más allá, propio de las artes y de las ciencias, llevó a Berrocal a la búsqueda y exploración de la cuarta dimensión como pocos, tal vez ningún escultor.

"La acumulación de formas, separadas entre sí por el vacío, resalta la cuarta dimensión", leemos en la quinta acuarela. Esa acumulación de formas es la materia descompuesta, primero en la representación de los dibujos, luego en la realidad, cuyo límite linda siempre con el vacío. Con sus piezas desmontables Berrocal nos invita a adentrarnos en el interior, en el lado rara vez visible de la materia.

Con la sexta y la séptima acuarelas cambiamos de tema: "La caligrafía puede ser un punto de partida de la inspiración". Se refiere a una de sus fuentes de inspiración, y apunta a la técnica de la caligrafía, que en la historia de Oriente ha sido una práctica más recurrente. Recordaba el poeta y ensayista José Ángel Valente que "la pintura, en la tradición china, sea históricamente tributaria de la escritura". La pintura se "escribe". Para el nacimiento de la visión interior en la que la inspiración o el tema se configuran, era frecuente que los pintores buscaran estímulo en la lectura de poemas" (Valente: 2002: 34). El diálogo entre la pintura y la literatura es imperecedero. Aquí tenemos otra muestra de la confluencia de artes en la obra de Berrocal.

"Las palabras pueden existir como formas, no sólo como signos", leemos en la séptima acuarela, que es una glosa, una consecuencia lógica de la anterior. Como declarara Goethe, el arte consiste esencialmente en dar forma. Las palabras, que son signos, pueden construirse artísticamente, de modo que forma y fondo se expresen en consonancia.

Y con la última de las acuarelas ( fig.04) da un inesperado giro, pues en lugar de proseguir la reflexión artística sobre el proceso de creación parece que una nueva felicidad lo ha desviado de su intención inicial, como un niño pequeño que juega y descubre otro placer. Y con ello no le resto importancia, al contrario. Estoy pensando en la idea de superhombre de Nietzsche, íntimamente vinculada con la inocencia de un niño creador que acepta el devenir mientras juega creando y destruyendo, como la naturaleza.

Esta última acuarela está dedicada a Rabbi Moshe Ben Maimon, más conocido popularmente como Maimónides (1135-1204), nacido en Córdoba y del que entonces se cumplía el 850 aniversario de su nacimiento. Unos años después, en 1987, realizaría el Opus 318, Maimónides, un bronce desmontable en 13 elementos. Pero más allá de estas anécdotas, la obra más célebre de Maimónides es Guía de perplejos, en la que podemos leer pasajes como este: "Enseñe a tu lengua para decir 'No sé y el progreso harás" (Gámez Millán, 2016: 28).

Remite esta idea en último término a Sócrates, para quien el saber procede del reconocimiento de la ignorancia. No sólo se trata de un aspecto común a la filosofía y las ciencias, que se regeneran y nos permiten progresar gracias a dicho reconocimiento, sino también a las artes. A diferencia de los artesanos, que saben a dónde se dirigen con su técnica, los artistas caminan a tientas, reconociendo continuamente "no sé", sin saber muy bien a dónde ir. Pero precisamente por ello son más experimentadores e innovadores, de tal modo que pueden descubrir mundos desconocidos, mundos que no son de este mundo pero que se pueden incorporar a nuestro mundo. 


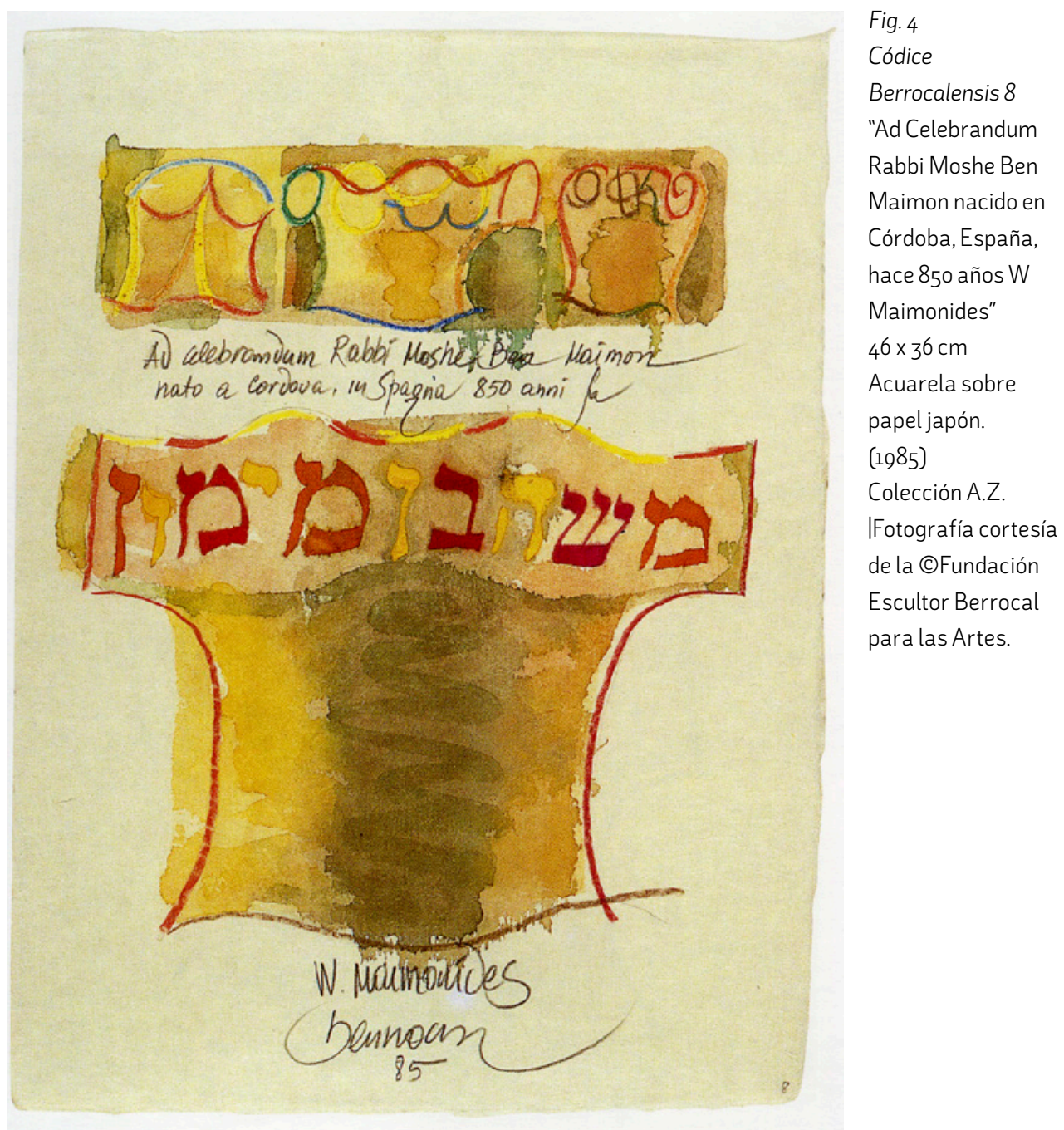

\section{Estética interactiva.}

El concepto "estética interactiva" se usa desde hace unos años para acá, cuando en sentido riguroso no hay arte que no presuponga una interacción entre la obra y un receptor. El arte es irremediablemente dialógico. Incluso en obras muy herméticas y solipsistas. Pues la conciencia del autor se forja en diálogo con la sociedad de su época. Todavía más, ya Aristóteles en la Poética y en la Retórica mantuvo que el artista ensaya los posibles efectos que quiere suscitar con la obra en primer lugar consigo mismo (Aristóteles: 2004: 78). Y este desdoblamiento del autor convertido en crítico es ya un ejercicio dialógico.

Como consecuencia de la desmontabilidad, que le permite adentrarse por lo que se ha denominado la cuarta dimensión, muchas de las piezas de Berrocal son particularmente interactivas. No basta con mirarlas, no están de modo único y exclusivo concebidas para ser contempladas, sino para que los receptores jueguen con ellas desmontándolas y montándolas. Con ello pretendía acercar la escultura al público. 
Sin embargo, si interactuamos desmontando y montando las esculturas como si fuera un juego se puede poner en tela de juicio un rasgo que tradicionalmente ha sido constitutivo de las artes, la distancia estética. ¿Podemos hablar de arte sin distancia estética? Dado que Nietzsche y Gadamer criticaron el supuesto desinterés del juicio estético según Kant, mi hipótesis al respecto es que el arte posee múltiples funciones, no es sólo objeto de contemplación, también posee valores performativos, aspira a encarnarse y a habitar de otro modo el mundo.

Curiosamente, en ocasiones para comprender adecuadamente una obra se requiere introducirnos por el proceso de creación del artista. Durante el siglo XX se ha resaltado la importancia del proceso, que equivale al método, por encima del resultado. Con muchas de sus piezas Berrocal nos invita en cierto modo a (re)construir este proceso, a desmontar y montar.

Además de nuestra imaginación espacial, con esta práctica desarrollamos nuestra sensibilidad y nuestra percepción. Tradicionalmente hemos pensado que los sentidos actúan de manera independiente. Por recientes investigaciones en neurología sabemos que se necesita el movimiento del cuerpo (Eagleman, 2017: 59) y la interacción de los demás sentidos de manera conjunta. De tal modo que con el tacto de las manos podemos palpar y "ver" lo que no se muestra a simple vista. La percepción de unos sentidos complementa y amplía la de otros.

Así uno puede aprender jugando con las esculturas desmontables de Berrocal, que sigue siendo a mi parecer una de las formas más valiosas y eficaces de aprender, pues lo hacemos sin apenas esfuerzo, impulsados y motivados por el juego que absorbe nuestra atención y concentración. Lo difícil reside a menudo en aprender que algo nos guste; si conseguimos que nos guste, como ocurre con el juego, el estudio-trabajo marcha guiado por la motivación del placer.

Desde una perspectiva antropológica y filosófica, el mejor estudio que conozco sobre la importancia del juego en la condición humana es el clásico Homo ludens, de Johan Huizinga. Pero las páginas que le dedica a las artes plásticas son pocas y no muy esclarecedoras (Huizinga, 1998: 286-293). Por el contrario, Schiller declaró en sus Cartas sobre la educación estética algo que merece retenerse: "el hombre solamente juega cuando, en el sentido completo de la palabra, es hombre y solamente es hombre completo cuando juega" (Schiller, 1981: 92-93).

Evidentemente, si bien hay una intención estética y comunicativa en las esculturas de Berrocal, desde el punto de vista del receptor son "obra abierta" tal como lo definió Umberto Eco: "como proposición de un campo de posibilidades interpretativas, como configuración de estímulos dotados de una sustancial indeterminación, de modo que el usuario se ve inducido a una serie de 'lecturas' siempre variables" (Eco, 1984: 172). Es, en términos de Kant, el libre juego de la imaginación y el entendimiento.

Al tratarse de obras abiertas el significado permanece indeterminado. Es una experiencia que debe construir el receptor (Dewey, 2008: 41-65). Como señala el neurólogo David Eagleman, "el significado que tiene algo para usted depende de sus redes de asociaciones, que se basan en la historia total de sus experiencias vitales" (Eagleman, 2017: 46). Tesis que parece confirmar de momento la revolución copernicana continuada por Kant al mantener que es el sujeto el que desde un punto de vista epistemológico configura en buena medida al objeto; revolución precedida por Descartes, precursor de la subjetividad moderna. 


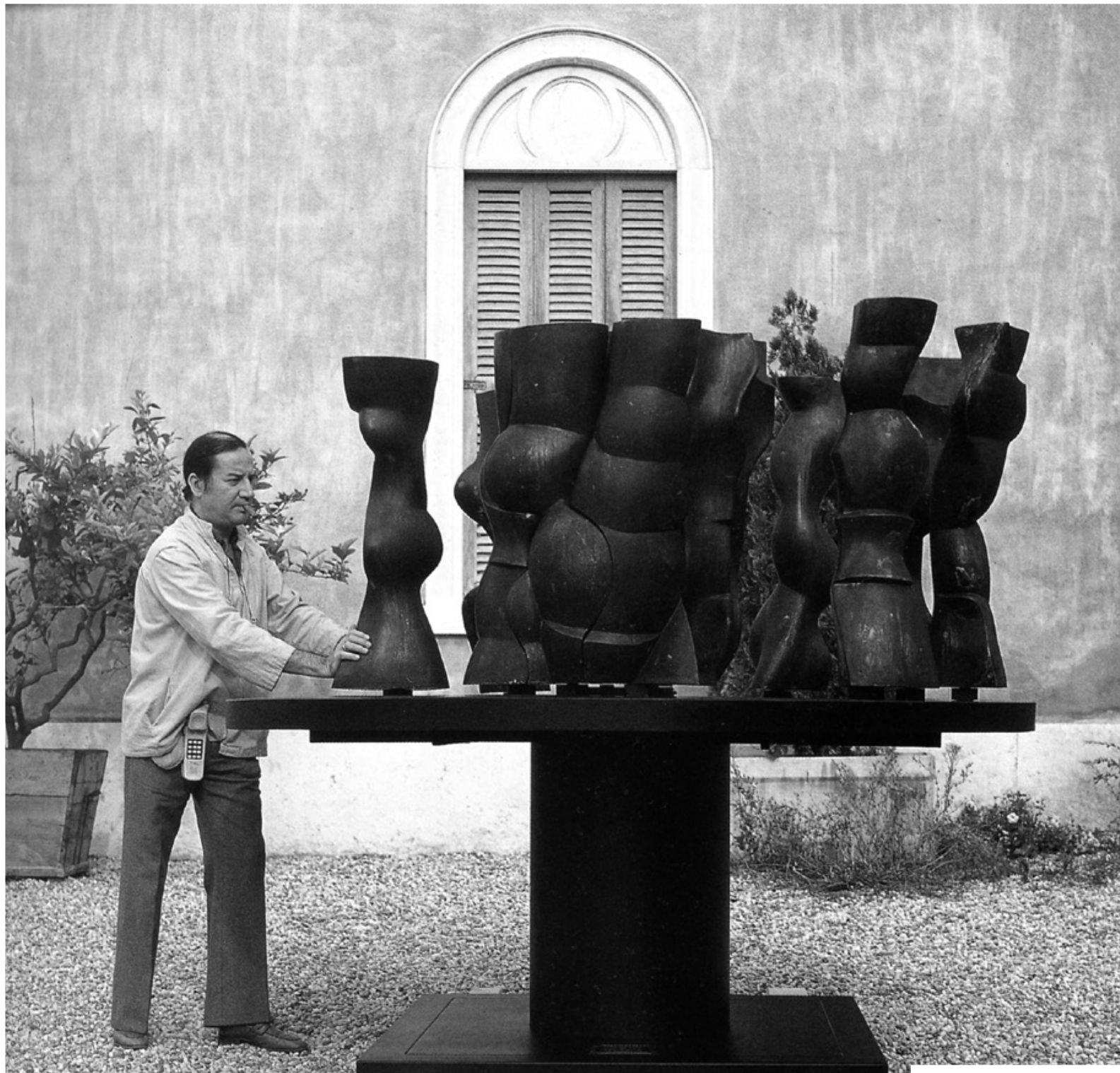

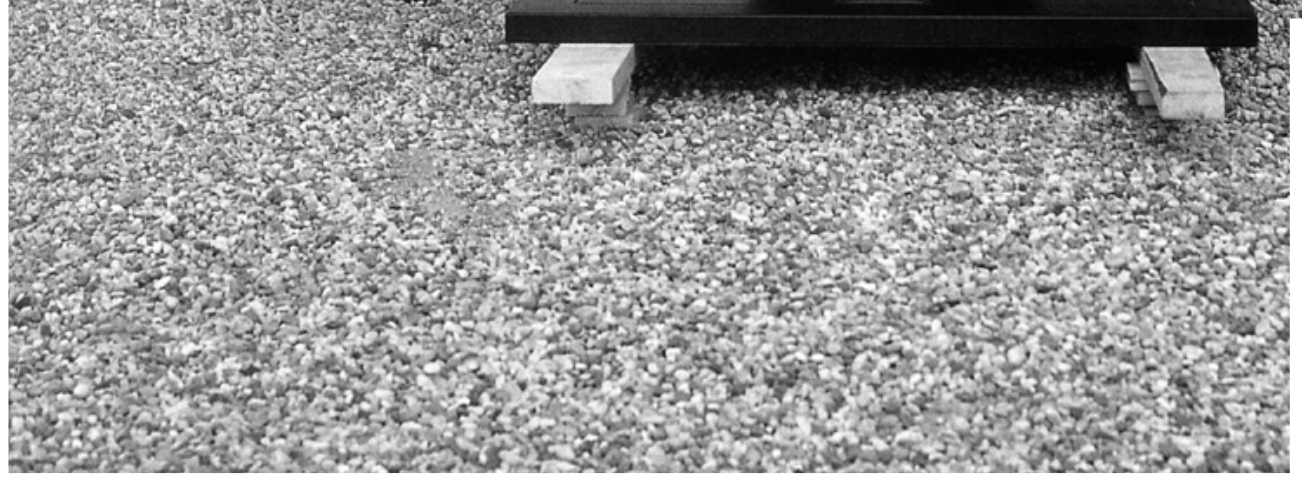

En otro plano de la estética interactiva, si se atribuye a Calder la creación de los móviles, esculturas dibujadas con alambre y otros materiales, Berrocal va más allá en el movimiento de las esculturas, pues mientras las esculturas del primero se mueven al son del aire, algunas
Fig. 5.

Torso Cerruti

(Opus 172)

$1,94 \times 1,20 \times 1,20 \mathrm{~m}$

Bronce, móvil,

transformable,

once elementos.

(1979)

Fotografía cortesía de la (C)Fundación Escultor Berrocal para las Artes 
obras del segundo, como Opus 172, Torso Cerruti (1979) fig.05 y Opus 402, Citius Altius Fortiius (1991) fig.o6 (VVAA, 2000: 54-57 y 60-65), adquieren movimiento por una técnica mecánica concebida por el artista.

No se trata de un mero adorno o juego en su sentido más superficial: es una técnica con el fin de apreciar en el despliegue del movimiento otras cualidades escultóricas sin que necesariamente los espectadores estén moviéndose, lo que nos puede permitir una observación más completa y enriquecedora. Por todo ello la obra de Berrocal es un paradigma de la estética interactiva de la escultura. 


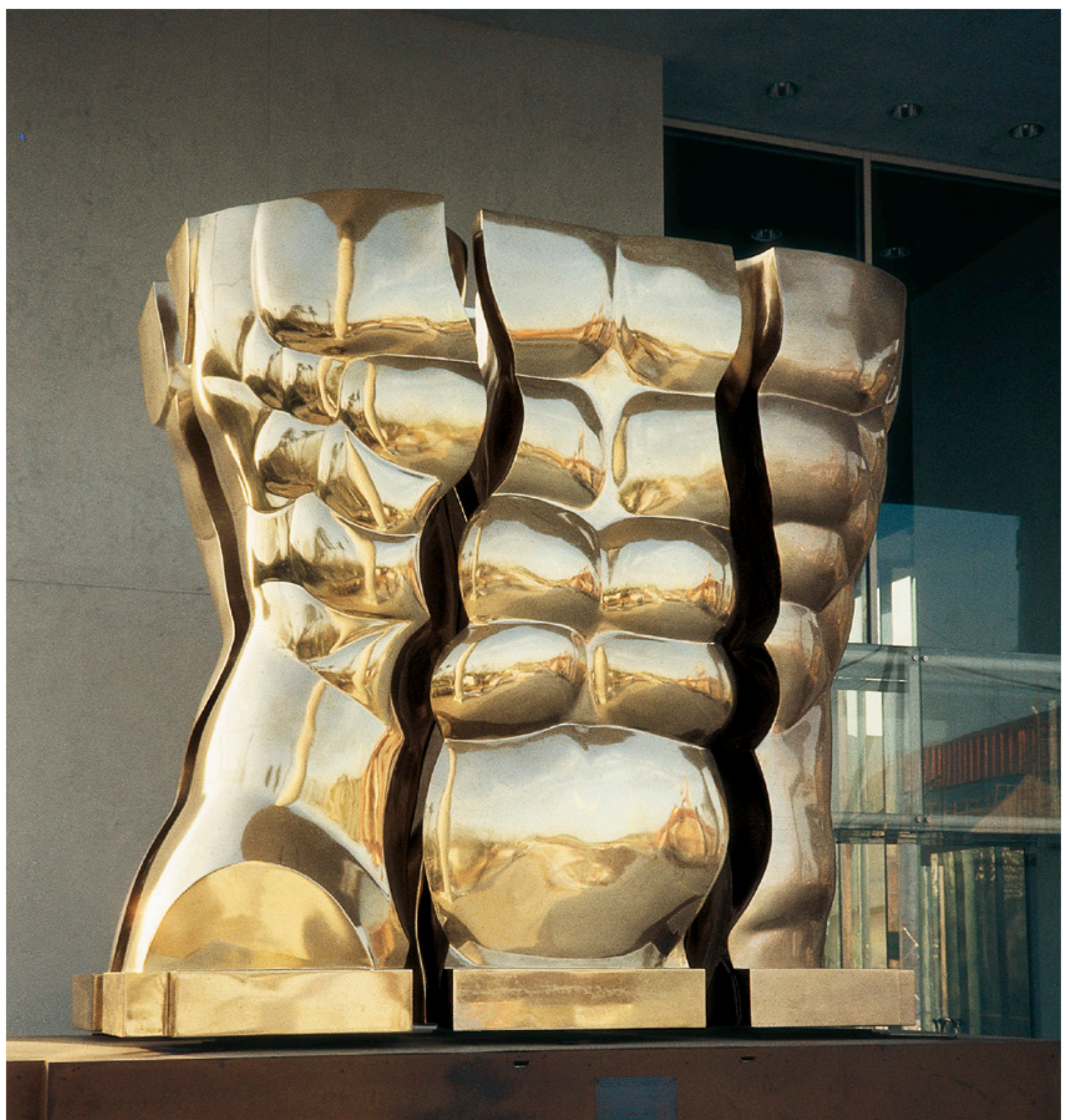

Fig. 6.

Citius Altius Fortius

(Opus 402)

Musée Olympique

Lausana

$3 \times 1 \times 0,60 \mathrm{~m}$

(1991)

Fotografía cortesía de la (C) Fundación Escultor Berrocal para las Artes 


\title{
Referencias Bibliográficas / References
}

\author{
ARISTÓTELES (2004). Poética. Trad. Alicia Lecumberri, Madrid: Alianza.
}

AzÚA, Félix (2017). Diccionario de las Artes. Barcelona: Debate.

BERGER, John (2017). Sobre el dibujo. Trad. Pilar Vázquez, Barcelona: Gustavo Gili.

BOTTON, Alain de, y Armstrong, John (2018). El arte como terapia. Trad.

Ricardo García y Elena Aranaz, Hong Kong: Phaidon.

BOZAL, Valeriano (1997). Historia de las ideas estéticas I,. Madrid: Historia 16.

BOZAL, Valeriano (1998). Historia de las ideas estéticas II.Madrid: Historia 16.

DEWEY, John (2008). El arte como experiencia. Trad. Jordi Claramonte, Barcelona: Paidós.

EAGLEMAN, David (2017). El cerebro. Nuestra historia. Trad. Damià Alou, Barcelona: Anagrama.

Eco, Umberto (1984). Obra abierta, trad. Roser Berdagué. Barcelona, Planeta.

GÁMEZ MILLÁN, Sebastián (2018) Conocerte a través del arte. Madrid: Ilusbooks.

GÁMEZ MILLÁN, Sebastián, (2019). "Estudio-Taller Berrocal: experimentar de otro modo el museo", en Diferents, Revista de Museus, nำ4, pp. 62-73.

Gámez Millán, Sebastián, (2016). Cien filósofos y pensadores españoles y latinoamericanos, Madrid: Ilusbooks. HUIZINGA, Johan (1998). Homo ludens, trad. Eugenio Imaz, Madrid, Alianza.

GoULD, Stephen Jay (2010). Érase una vez el zorro y el erizo. Las humanidades y las ciencias en el tercer milenio, trad. Joandomènec Ros, Barcelona, Crítica.

GoULD, Stephen Jay, (2007). Acabo de llegar. El final de un principio en historia natural, trad. Joandomènec Ros, Barcelona, Crítica.

KANT, Immanuel (2003). Crítica del discernimiento, trad. R. Rodríguez Aramayo y Salvador Mas, Madrid: Antonio Machado.

MARINA, José Antonio (2000). Teoría de la inteligencia creadora, Barcelona: Anagrama.

MARINA, José Antonio (1992). Elogio y refutación del ingenio, Barcelona: Anagrama.

ORTEGA y GASSET, José (1977). Meditación de la técnica, Madrid: Revista de Occidente.

SANTAYANA, George (2002). El sentido de la belleza. Un esbozo de teoría estética, trad. Carmen García Trevijano, Madrid: Tecnos.

SENNET, Richard (2009). El artesano, trad. Marco Aurelio Galmarini Rodríguez, Barcelona: Anagrama.

SCHILLER, Friedrich (1981). Cartas sobre la educación estética del hombre, trad. Vicente Romano García, Madrid, Aguilar.

SHUSTERMAN, Richard (2002). Estética pragmatista. Viviendo la belleza, repensando el arte. Trad. Fernando González del Campo Román, Barcelona: Idea Books.

STEINER, George (2001). Gramáticas de la creación. Trad. Andoni Alonso y Carmen Galán Rodríguez, Barcelona: Círculo de Lectores. 
TATARKIEWICZ, Wladyslaw (2016). Historia de seis ideas: arte, belleza, forma, creatividad, mímesis, experiencia estética. Trad. Francisco José Marín, Madrid: Tecnos.

VALENTE, José Ángel (2002). Elogio del calígrafo. Ensayos sobre arte. Barcelona: Galaxia Gutenberg-Círculo de Lectores.

VALÉRY, Paul (2007). Cuadernos. Trad. Maryse Privat, Fátima Sainz y Andrés Sánchez Robayna, Barcelona: Galaxia Gutenberg-Círculo de Lectores.

VVAA. (2000). Berrocal. Madrid, Unicaja.

WAGENSBERG, Jorge (2014). El pensador intruso. El espíritu interdisciplinario en el mapa del conocimiento. Barcelona: Tusquets.

WAGENSBERG, Jorge (2019). Teoría de la creatividad. Eclosión, gloria y miseria de las ideas. Barcelona: Tusquets. 
